\section{Reni Marchevska}

Profesora Titular de Literatura Hispanoamericana de la Universidad «San Cirilo y Metodio», de Veliko Tarnovo (Bulgaria). Ha publicado diversos artículos sobre autores hispanoamericanos. En la actualidad ha centrado su interés en la última narrativa hispanoamerica y más concretamente en el género del cuento. Tiene compilados dos volúmenes antológicos de cuentos hispanoamericanos: Espejos Cóncavos (Sofia, Heizel, 2000) y El cuento hispanoamericano actual (Sofia, 2000), antología muy destacable consumada en el Grupo Latinoamericano de Sofia.

\title{
UNA MIRADA HACIA «LOS NUDOS DEL SILENCIO»DE RENÉE FERRER
}

\author{
RENI MARCHEVSKA
}

En el marco de la literatura hispanoamericana escrita por mujeres, Los nudos del silencio comparte algunas de las características temáticas de las obras que cuestionan los papeles tradicionales en la sociedad patriarcal y la marginación social, económica y cultural de la mujer. Desde perspectivas distintas, la deconstrucción de los valores hegemónicos y la relativización de las jerarquías indiscutibles han sido el blanco de narradoras como la colombiana Fanny Buitrago, la argentina Reina Roffe, las uruguayas Cristina Peri Rossi y Tereza Porzecanski, las puertorriqueñas Ana Lydia Vega y Rosario Ferré, la chilena Diamela Eltit o la mexicana Angeles Mastretta, por mencionar algunas.

Al firme propósito de romper con el aislamiento y el vasallaje de la mujer se suman también los esfuerzos de la escritora paraguaya Renée Ferrer en su primera incursión en la novela. El enfoque feminista, sin embargo, no premia sólo y exclusivamente la explotación de la mujer por el varón. Esta temática se inscribe en un contexto mayor - el ejercicio del poder en los estados de gobierno totalitario-. A la par con una sutil penetración en las almas de los personajes, Ferrer combate los pilares que sustentan el estereotipo de la mujer como esposa y madre sumisa y abnegada y el mito del macho prepotente, cabeza de familia y por tanto única autoridad para sus miembros, pero condena también la agresión y el poder en todas sus manifestaciones. La historia del $\mathrm{Pa}$ raguay esta marcada por episodios horripilantes, violencia y sangre. El profundo marasmo en que la última dictadura sumió al país dejó profundas heridas en la conciencia nacional. El ambiente de asfixia y agobio subyace en to- dos los niveles de la obra. En este sentido, se desprende de Los nudos del silencio una honda preocupación por el respeto de las libertades y la dignidad humanas y un agudo juicio sobre el ejercicio deliberado del poder en todas sus dimensiones: política, social, económica y cultural.

La aplastante realidad paraguaya trasciende en la novela de Ferrer los limites de un país concreto para abarcar - a través de la alusión a los bombardeos contra Vietnam - a todos los países que han padecido o siguen padeciendo el peso de la monstruosa pirámide de la opresión. Cruce de ideas progresistas, Los nudos del silencio adquiere universalidad también por la excepcional prosa lírica, independiente de convencionalismos escriturales y moldes genéricos, dotada de una mayor atención al lenguaje y un trabajo más cuidadoso sobre las estructuras y los recursos narrativos que va aboliendo la censura y la univocidad de sentido a favor de un compromiso abierto con la problemática tratada y una perdurabilidad y efectividad política, social y estética. El argumento, resumido en pocas palabras, se centra en las relaciones interpersonales de un matrimonio de la burguesía paraguaya - Manuel y Malena - que se va de viaje a París. De gustos distintos - a ella le gusta la música clásica, a él los espectáculos eróticos-, Manuel no quiere oír las súplicas y las protestas de su esposa, criada con la rígida moral de la sociedad patriarcal, y en vez de acompañarla al concierto que ella había elegido, la lleva, contra su voluntad, a un burdel de ínfima categoría donde «se ofrecen emociones reservadas para unas pocas personas». Hundida en la butaca, casi invisible, entre «hombres solos masticando 
una lujuria que no intentaban esconder», $\mathrm{Ma}$ lena mira el escenario donde bailan dos vietnamitas - Luis y Mei Li-. Las expectativas de Manuel de disfrutar de un porno-show que afirme la superioridad del hombre se ven frustradas por las escenas lésbicas que protagonizan las dos mujeres. Humillado más que decepcionado, Manuel insiste en abandonar el lugar, pero Malena se niega a obedecer su orden, intrigada por las relaciones desconocidas por ella que el espectáculo ofrece.

A partir de este incidente en la vida conyugal de Malena y Manuel, Ferrer va construyendo una obra de compleja arquitectura y múltiples resonancias. Sobre el espacio blanco de las páginas se va imprimiendo el espacio cerrado de la represión política, la opresión familiar y la soledad de la mujer sometida: enorme «nudo» de impenetrables silencios que oprime la garganta.

Mas allá de la experimentación lingüística y formal, Ferrer ahonda en el devenir humano y la temática de la libertad individual, la ruptura del aislamiento - la comunicación, el amor, la solidaridad-y la búsqueda de la trascendencia - social, metafísica o humana-. En su relación con Manuel, Malena ha adoptado siempre por la actitud pasiva. Como toda mujer casada, está sujeta a su marido, quien la humilla y protege alternativamente, convirtiéndola en un animalito de adorno que se trata con desdeñosa benevolencia. El abuso del poder, práctica cotidiana para el torturador que presta sus servicios al régimen, se extiende también a sus relaciones conyugales. $\mathrm{Ne}$ gándole una realidad propia a Malena, Manuel promulga sus leyes, defiende su libertad personal, su supremacía como individuo y su propiedad, parte de la cual es su esposa. El silencio es la máscara que pone para ocultar los crímenes en que participa y su verdadera naturaleza, homologada por Malena con la de las bestias. El espacio de la dictadura - perfectamente identificable, delimitado, con sus lugares de tortura y sufrimiento-, y el del patriarcado, a cuyos cánones se ha de ajustar toda pareja que se quiere respetable, resultan relevantes para la organización del contenido y el mensaje de la obra. Descrita con un lenguaje violento - «el agua grita turbia en la pileta donde flotan los sollozos, los pedidos de clemencia, las blasfemias, finalmente, el silencio» (pág. 140) - la imagen de la dictadura y sus métodos, como una de las caras del poder,

está personificada por Manuel, copia en miniatura del dictador latinoamericano. La impunidad alimenta y reafirma su arrogancia, su orgullo de pertenecer a la única especie dotada de inteligencia suficiente para participar en el gobierno del país y tirar las riendas de los asuntos familiares. A su actitud cínica la autora contrapone el estereotipo de la mujer abnegada. Fingir, siempre en silencio, «acuclillada tras los barrotes del silencio»: imagen que define no sólo a Malena, sino a todas las mujeres cuya existencia esta marcada por las normas morales de la sociedad patriarcal y la opresión del varón. Tragarse todos los sorbos amargos, sin la menor resistencia. Renunciar has-

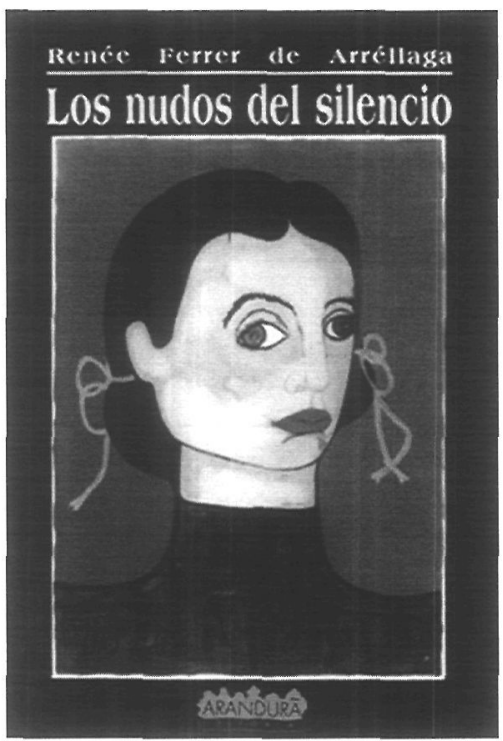

Los nudos del silencio. Portada. (llustración de María Cristina Aragón). ta a los sueños más íntimos con tal de hacer feliz al hombre que se ama y respeta. En el pequeño burdel parisino, Malena se enfrenta con una relación chocante, insólita para su educación. El sexo - uno de los temas que traduce la ambigüedad-, permite la contraposición de los protagonistas y la oposición de maneras distintas de entender las relaciones amorosas. Una, la del hombre, movido únicamente por las bajas pasiones; y la otra, que busca su dimensión humana. Un abismo separa a $\mathrm{Ma}$ nuel y Malena que comparten el mismo lecho, mas por motivos distintos. Su concepto de la relación sexual queda perfectamente delineado por los pensamientos que provoca en ambos el espectáculo lésbico: «¿Cómo será en la cama semejante especimen, se pregunta intrigado Manuel, que no puede parar el empuje de su torrentosa imaginación?» / «QQué destino el de los hombres, tan semejante al de las bestias, cuando el orgasmo se vuelve mero detalle en la horizontal selva de la entrega! (...) ¿Y los temblores del alma? ¿Y ese explorarse en el deseo como si estuviéramos desvistiendo una fruta madura?». Los recuerdos y las reflexiones de Malena, por una parte, y el punto de vista de Manuel, por otra, permiten a la autora participar en el discurso de los personajes e insertar una serie de observaciones sarcásticas acerca de la diferencia entre hombres y mujeres en lo referente su vida emocional y sus relaciones con el poder del varón. La homosexualidad femenina, que en la novela dista de lo obsceno y lo vulgar, opone la sensibilidad y los auténticos afectos a la bru- 


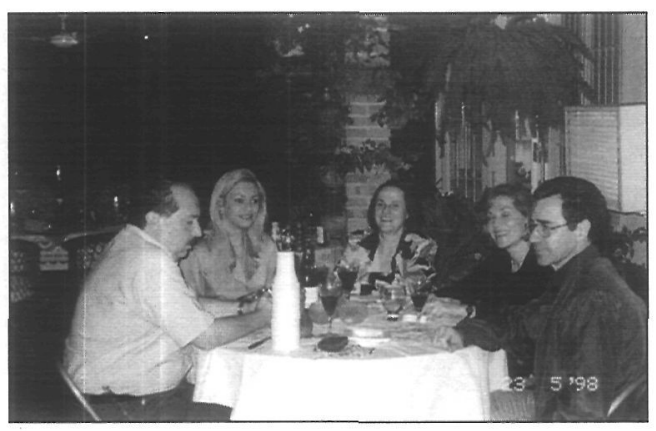

Helio Vera, Reneé Ferrer, $M^{a}$ Elena Villagra y Guido Rodríguez Alcalá. (Foto: Mar Langa). talidad y a la violencia, latente en todos los niveles del texto, con implícitas remisiones a la realidad extralingüística. En la repulsa y el desdén con que Malena mira a la vietnamita, se introduce, paulatinamente, siguiendo las fugas del saxo, algo que desconcierta y remueve la conciencia, algo que va anulando los valores de una sociedad machista, autoritaria, falsa, puritana. Comunicación extraña la que en la noche establecen los ojos. Comunicación que no necesita de palabras para reconocer y transmitir la profunda soledad y el sufrimiento. A partir de este pacto secreto, donde el lenguaje verbal como vía de comunicación estorba, se produce en Malena una profunda transformación: la toma de conciencia - primer paso hacia la libertad individual-.

El viaje de la protagonista por algunas de las posibilidades sensoriales que las relaciones sexuales entre mujeres pueden despertar, podría ser también una respuesta al viejo debate: ¿tiene que estar la sexualidad de la mujer limitada siempre a la del hombre? Este interrogante que inevitablemente suscita la lectura de la novela, no aboga explícitamente por el lesbianismo, sino que sustenta y refuerza el cuestionamiento de la visión equivoca, parcial e inconsistente que en las sociedades patriarcales se tiene de la plenitud de una relación y el derecho a la libertad individual en la elección del propio destino.

El mero hecho de situar la historia en un burdel y la presencia de Mei Li como protagonista del show apunta a otra preocupación: la de la prostitución y sus causas. En París, símbolo del progreso y de las nuevas ideas, la mujer sigue siendo objeto de maltrato y abuso sexual. Los mismos hombres defensores de la virtud y de la honestidad femeninos, que simulan fidelidad y respeto por los sagrados códigos del matrimonio, infringen las normas en cuya redacción tuvieron parte y adaptaron a su conveniencia. La contemplación que se da en los relatos de segundo orden - que confieren mayor objetivismo y veracidad al relato principal- converge en la formación de un clima de delirio, de «niebla» y «bruma». El fluir de la conciencia de Mei Li corre atrave- sando los lugares mas recónditos de su vida. Se confunden las imágenes; el pasado y el presente son una sola imagen: la miseria. «Una niebla de arroz se levanta desde las escudillas llenas (...)», "Se confunde con el azul de las butacas: la niebla. (...)», "Canela y anís. Canela y anís. (...) Canela y anís me persiguen. Olores. Momentos. Delicias, que no se si existieron o son puro sueño. El hambre se derrama dentro de mí. (...) Y todos llevamos el hambre tatuada en los ojos». El papel que la vietnamita desempeña para la evolución de Malena y su toma de conciencia viene justificado precisamente por la amarga experiencia de mujer que ha crecido en miseria y miedo al terror y la agresión, dominada y explotada - en su país primero, en Francia después -; de un cuerpo sellado para siempre por las marcas de la injusticia y la brutalidad.

La sensación de distancia y ausencia que Mei Li experimenta bailando, se hace mas nítida conforme avanza el espectáculo: «No soy aquí, prisionera de esta complacencia ajena, frente al insano placer de bocas ávidas y ojos voraces, sino en aquel tiempo primigenio, cuando aún era germen, bosquejo, perspectiva, y mis pasos eran pequeños. Lejos de este cuerpo que se doblega a los retorcimientos del saxo. Antes de mi primer recuerdo». Refugiarse en la infancia, en la inocencia, para poder soportar el pesado bulto de injusticias y de explotación. Lo mismo Mei Li que Malena se alimentan del pasado: una para olvidar, la otra para salir de la inercia y encontrar el camino hacia la independencia y la felicidad. Las notas persistentes del saxo provocan y se retiran dejando que Malena se sacuda del letargo y se decida a abandonar a Manuel. El destronamiento de la palabra autorizada y autoritaria en beneficio de una interacción verdaderamente dialógica es logrado con distintos recursos estilísticos propios de la poesía que enfatizan el significado de las palabras y anuncian el clímax. El silencio - clave para las múltiples interpretaciones que permite el texto- oculta las huellas del crimen y ahoga los gritos de las víctimas; es presencia, inexistencia y ausencia; es mutuo acuerdo y resignación, pero es también resistencia y rebeldía.

La novela coloca a la mujer como protagonista no porque sea su discurso el que prevalece, sino porque se convierte en sujeto de la acción, y con su acción se transforma y transforma a los demás. La subversión de los 
papeles tradicionales que atribuyen el papel activo del hombre y el pasivo a la mujer sugiere una reinterpretación de la feminidad y lo femenino reconociendo y revalorizando lo intrínsecamente femenino y aquello que le ha sido atribuido por la sociedad. La concienciación de Malena es símbolo de la mujer que vence el dogmatismo del patriarcado, pero es también símbolo del triunfo de la democracia en Paraguay con la subsiguiente apertura de la sociedad paraguaya al exterior. El manojo de sogas que Malena desata al terminar el espectáculo, "corrigiendo la curva endurecida por los años» remite asimismo a ese emerger del silencio de una nueva hornada de escritoras paraguayas que nos entregan obras de indudable calidad artística; obras de trascendencia nacional, continental y universal.

\section{BIBLIOGRAFÍA Y REFERENCIAS}

ALVAR, MANUEL, «Los murmullos opacos de la noche, sobre «Los nudos del silencio» de Renée Ferrer, op. cit., pp. 239-242. ECO, UMBERTO, Lector in fábula. La cooperazione interpretativa nei testi narrativi, Ed. Bompiani, Milán, 1979.

FALCÓN, LIDIA, Mujer y sociedad. Barcelona, Fontanella, 1984.

FERRER, RENÉE, La narrativa Paraguaya (L II), en «Marcha», Tercera época, año XII, no 138, abril 1998, edición electrónica.
FERRER, RENÉE, Los nudos del silencio, Asunción, Arandurâ, 1992.

FOSTER, DAVID WILLIAM: «Introducción a Los nudos del silencio», op. cit., pp. 7-10.

GENET'TE, GÉRARD, Palimpsestos. La littéra-

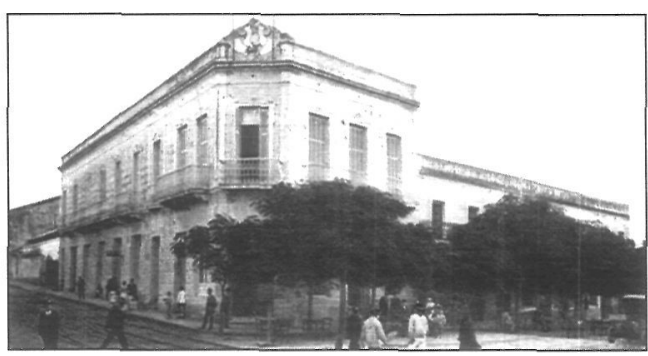

Asunción. (Foto: Archivo Jorge Rubbiani). ture au second degré, Edt. Du Seuil, Paris, 1982.

KANEV, VENKO, «El lenguaje poético» en Nociones teóricas de la estilística del texto literario, Sofia, 2000.

PACHECO, CARLOS, Narrativa de la dictadura y crítica literaria. Caracas, CELARG, 1987.

PARTYKA, BETSY: «Rompiendo las cadenas en Los nudos del silencio", op. cit., 211-215.

PEIRÓ, BARCO, JOSÉ VICENTE, edit.: «Portal de literatura paraguaya». En www.cervantesvirtual.com

PEIRO, JOSÉ VICENTE, «Erotismo y escritura antiautoritaria» en Los nudos del silencio. Estudios críticos, pp. 251-270. También en Daniel BALDERSTON edit.: Sexualidad y nación, Pittsburgh, Instituto Internacional de Literatura Iberoamericana (Biblioteca de América), 2000, pp. 199-212.

RÍSQUEZ, F. Aproximación a la feminidad Caracas, Monte Ávila, 1991. 